\title{
DFT+U Study on the Oxygen Adsorption and Dissociation on
}

\section{$\mathrm{CeO}_{2}$-Supported Platinum Cluster}

Tien Quang Nguyen ${ }^{1}$, Mary Clare Sison Escaño ${ }^{1 *}$, Hiroshi Nakanishi ${ }^{1}$, Hideaki Kasai ${ }^{1 \dagger}$, Hiroyoshi Maekawa ${ }^{2}$, Kazuo Osumi $^{2}$, Kaoru Sato ${ }^{2}$

${ }^{1}$ Department of Precision Science \& Technology and Applied Physics, Graduate School of Engineering, Osaka University, 2-1 Yamadaoka, Suita, Osaka 565-0871, Japan

${ }^{2}$ ISUZU Advanced Engineering Center, Ltd., 8 Tsuchidana, Fujisawa, Kanagawa 252-0881, Japan

\begin{abstract}
We investigated the reactivity of $\mathrm{CeO}_{2}$ - supported $\mathrm{Pt}_{4}$ cluster (denoted as $\mathrm{Pt}_{4} / \mathrm{CeO}_{2}(111)$ ) towards $\mathrm{O}_{2}$ adsorption and dissociation as well as the geometry/electronic properties associated with such metal oxide supported cluster system using Density Functional Theory and on-site Coulomb interaction correction via the Hubbard-like term, U (DFT+U). It was found that $\mathrm{Pt}_{4}$ binds strongly to $\mathrm{CeO}_{2}(111)$ via Pt-O-Ce bonds which act as "anchors" between the surface and the cluster, confirming its non-sintering as found in experiments. The adsorption of the cluster involves net electron transfer to $\mathrm{CeO}_{2}$, however, charge redistribution also happens within the cluster (from Pt atom bonded to the surface to the Pt on top of the cluster). This charge couples to the top Pt leading to reduce its spin moment as compared to that of unsupported cluster. When $\mathrm{O}_{2}$ adsorbs on $\mathrm{Pt}_{4} / \mathrm{CeO}_{2}(111)$, while it prefers $\mathrm{Pt}$ vertex site near the $\mathrm{CeO}_{2}$ surface, the $\mathrm{O}-\mathrm{O}$ bond elongation is more profound at the Pt-Pt edges. The energy barrier for dissociating $\mathrm{O}_{2}$ from this edge site precursor state is smallest. A correlation between the O-O bond length at the precursor state and the stability at the transition state is revealed. Finally, the barrier for dissociation in unsupported $\mathrm{Pt}_{4}$ is lower, indicating suppression of the cluster's reactivity due to the support. We
\end{abstract}

\footnotetext{
*Present address: Graduate School of Engineering, University of Fukui, 3-9-1 Bunkyo, Fukui, 910-8507, Japan

†Corresponding author's e-mail: kasai@dyn.ap.eng.osaka-u.ac.jp
} 
attribute this to the hybridization of Pt-5d orbitals with $\mathrm{O}-2 \mathrm{p}$ orbitals in $\mathrm{CeO}_{2}(111)$ leading to the broadening of Pt- 5d states near the Fermi level.

\section{Introduction}

Air pollution from automobile exhaust is one of the major environmental problems in the modern civilization. In order to reduce harmful emissions from diesel engines, the Diesel Oxidation Catalyst (DOC) has been widely investigated. In DOC systems, carbon monoxide (CO) and hydrocarbons (HC) are oxidized to harmless chemical substances such as $\mathrm{H}_{2} \mathrm{O}$ and $\mathrm{CO}_{2}$, while nitrogen oxide (NO) is converted to $\mathrm{NO}_{2}$ for easy treating in Selective Catalytic Reaction (SCR) - another stage of Diesel Catalytic Converter [1-4]. DOCs have a honeycomblike, monolithic structure. The monolithic support is made either from metallic (stainless steel) or ceramic material and is coated with high porous oxides, such as $\gamma-\mathrm{Al}_{2} \mathrm{O}_{3}$ (alumina), $\mathrm{CeO}_{2}$ (ceria) and precious metals (on top), such as $\mathrm{Pd}, \mathrm{Pt}$, and $\mathrm{Rh}$ to increase the catalytic activity or to stabilize the structure of the catalyst. In DOCs, ceria provides multiple functions, one of which is to store excess oxygen under oxidizing (fuel lean) conditions and release it in reducing (fuel rich) conditions to oxidize $\mathrm{CO}$ and $\mathrm{HC}$, where the transformation between $\mathrm{Ce}^{4+}$ and $\mathrm{Ce}^{3+}$ occurs. This process allows the catalyst to operate over wide air-to-fuel ratio [5-7]. On the other hand, $\mathrm{CeO}_{2}$ is also widely used for stabilizing precious metal particles [8]. Experimentally, it has been reported that $\mathrm{Pt}$ particles in $\mathrm{Pt}_{\mathrm{x}} \mathrm{CeO}_{2}$ catalyst do not sinter during high temperature aging in the presence of oxidative environment [9-12].

Furthermore, oxidation process plays a very important role in DOC systems (e.g. HC conversion: $\mathrm{HC}+\mathrm{O}_{2} \rightarrow \mathrm{CO}_{2}+\mathrm{H}_{2} \mathrm{O}$ ) and so, an understanding of the interaction of the metal/metal oxide system with $\mathrm{O}_{2}$ is imperative. To date, there are numerous researches on the adsorption and dissociation of $\mathrm{O}_{2}$ molecules on the organic systems and the bimetallic surfaces [13-15] but very few have been done on noble metal clusters or noble metal cluster/metal oxide, for instance, Pt cluster on $\mathrm{CeO}_{2}$. Yoon et al. [16] investigated the molecular and dissociative adsorption of $\mathrm{O}_{2}$ on $\mathrm{Au}$ clusters without the presence of metal oxide support using density functional theory (DFT). Halachev et al. [17] studied the dissociative adsorption of $\mathrm{O}_{2}$ on the transition metal clusters in the presence of general subsurface oxygen using Extended Huckel Method, leaving the effect of subsurface on the electronic structure of the metal clusters unexplored. This lack of understanding of reactivity of metal clusters with the support motivates 
this work to tackle the reactivity of Pt cluster supported on ceria in relation to its wide application in DOC systems as described above as well as the supported cluster's geometry and electronic features. Specifically, in the reactivity, the energetics of the adsorption and dissociation of $\mathrm{O}_{2}$ on $\mathrm{Pt}_{4} / \mathrm{CeO}_{2}(111) \mathrm{p} 3 \times 3$ surface is studied. We chose $\mathrm{CeO}_{2}(111)$ because of its stability over other surfaces like (110) or (100) [18-20]. It is an important factor for stabilizing the metal cluster on the support surface and hence, preventing the small cluster from sintering effect. Furthermore, we draw the effects of $\mathrm{CeO}_{2}$ support. In terms of the geometry/electronic properties of the catalyst, the adsorption of $\mathrm{Pt}$ cluster on $\mathrm{CeO}_{2}$ support is investigated to verify the cluster's stabilization as observed in experiment [21]. In this work, the tetrahedron structure of the $\mathrm{Pt}_{4}$ cluster was chosen because of its relative stability over the planar rhombus cluster $[22,23]$. This characteristic is also retained when the cluster is placed on the ceria support. Our calculations show that, the tetrahedral cluster is about $0.68 \mathrm{eV}$ more stable on the $\mathrm{CeO}_{2}(111)$ surface as compared to the planar rhombus one. In addition, the $\mathrm{Pt}_{4}$ cluster size is used since it is large enough to capture both the "contact" and "non-contact" parts with the $\mathrm{CeO}_{2}$ surface and, at the same time, is small enough for reasonable computational cost. Indeed, Pozdnyakova et al. [24] prepared Pt-ceria catalysts containing 0.5-0.6 nm small Pt particles by using impregnation (IMP) method; making it possible for fabricating such a small clusters on surface.

\section{Computational Methods}

First-principles calculations are performed using the spin-polarized version of the Vienna ab initio Simulation Package (VASP) [25,26]. The Perdew-Burke-Ernzerhof (PBE) version of the Generalized Gradient Approximation (GGA) is used to describe the exchange-correlation [27]. The interaction between the core and valence electrons is treated by the Projector Augmented Wave (PAW) method [28,29]. The valence electron configurations of cerium, oxygen, and platinum are represented in a plane wave basis set with a kinetic energy cutoff of $500 \mathrm{eV}$. The Brillouin zone is sampled using a (11x11x11) Monkhorst-Pack [30] grid for bulk ceria and the Gamma-point for the large surface model. The structures are optimized until the Hellman-Feynman force exerted on an atom is less than $0.02 \mathrm{eV} / \AA$. For the systems with highly localized electrons, for instance, $\mathrm{CeO}_{2}$ (the localized electrons belong to $4 \mathrm{f}$ states), we included the on-site Coulomb interaction via the Hubbard-like term U (DFT+U) as introduced by Dudarev 
et al. [31], in calculating the lattice constant and the energy gap. The correction to selfinteraction error of standard DFT by introducing Hubbard-like parameter (U) will basically modify the electronic structure of support surface and hence, change the bonding/anti-bonding energy as well as the charge transfer between the $\mathrm{Pt}_{4}$ cluster and the $\mathrm{CeO}_{2}(111)$ surface. Therefore, the energetic results such as adsorption energy or the energy barrier for dissociation of molecular oxygen on ceria supported $\mathrm{Pt}_{4}$ are expected to change depending on the $\mathrm{U}$ parameter. Indeed, it is shown that the adsorption energies of atomic oxygen on $\mathrm{LaBO}_{3}(\mathrm{~B}=\mathrm{Mn}$, $\mathrm{Fe}, \mathrm{Co}, \mathrm{Ni}$ ) surface vary significantly with the selected value of $U$ parameters [32]. Previous theoretical work found that, by introducing a value of $\mathrm{U}^{\mathrm{f}}=5.0 \mathrm{eV}$ for $\mathrm{Ce} 4 \mathrm{f}$, the expected geometry structure of $\mathrm{CeO}_{2}$ can be reproduced [33]. However, other studies shown that when employing LDA/GGA to model O-derived p-type defect states in metal oxide, such as localized holes, the O $2 \mathrm{p}$ states correction for self-interaction error should be applied as well [34-38]. Later, Plata at al. [39] found that using a set of $U^{f}=5 e V$ and $U^{p}=5 \div 6 \mathrm{eV}$ (for $O 2 p$ ) leads to an improvement in describing the lattice parameters, band gaps, and formation and reduction energies of $\mathrm{CeO}_{2}$. Hence, in this work, we carefully checked different sets of $\left(\mathrm{U}^{\mathrm{f}}, \mathrm{U}^{\mathrm{p}}\right)$ and derived that the combination of $\mathrm{U}^{\mathrm{f}}=5 \mathrm{eV}$ and $\mathrm{U}^{\mathrm{p}}=5.5 \mathrm{eV}$ gives a good description of some critical aspects concerning the structure, electronic properties, and thermochemistry of ceria. With these values of Hubbard-like term, the lattice constant of bulk ceria is found to be $5.476 \AA$. This is very close to experimental value (5.411 $\mathrm{A})$ [12], and in good agreement with other theoretical data $[39,40]$. The $2 \mathrm{p}-4 \mathrm{f}$ and $2 \mathrm{p}-5 \mathrm{~d}$ energy gaps, $\sim 2.33 \mathrm{eV}$ and $\sim 5.33 \mathrm{eV}$, are also close to experimental and theoretical results $[39,41,42]$. The lattice parameter from bulk calculation of ceria was used in all the calculations for the surface.

Next, the ceria support is modeled by constructing the $\mathrm{CeO}_{2}(111)$ surface. $\mathrm{A} \mathrm{p}(3 \times 3)$ expansion of the (111) surface unit cell is used for $\mathrm{Pt}_{4}$ cluster adsorption. With this model, the shortest distance from the $\mathrm{Pt}_{4}$ cluster to the neighboring cluster is about $9.03 \AA$, sufficient to minimize cluster-cluster interaction. For the $\mathrm{CeO}_{2}$ surface, each slab includes 3 atomic layers with a sandwich structure, O-Ce-O, as shown in Figure 1a. This implies that the $\mathrm{CeO}_{2}(111)$ surface is terminated by oxygen atoms. We used two sandwich slabs (or six atomic layers) because, in this case, the convergence of the total energy with respect to slab thickness is achieved. A vacuum of $\sim 18.54 \AA$ is introduced to avoid the interactions in the $\mathrm{z}$-axis (perpendicular to surface) between neighboring supercells. For geometric optimization of 
$\mathrm{Pt}_{4} / \mathrm{CeO}_{2}$ (111), the $\mathrm{Pt}_{4}$ cluster and the first three atomic layers of $\mathrm{CeO}_{2}$ (from top of the surface) are fully relaxed, while others are kept constrained to bulk positions.

For the adsorption and dissociation of $\mathrm{O}_{2}$ molecule on $\mathrm{Pt}_{4} / \mathrm{CeO}_{2}(111)$, various initial adsorption sites are considered. The adsorption energies of the $\mathrm{O}_{2}$ molecule on $\mathrm{Pt}_{4} / \mathrm{CeO}_{2}(111)$ surface were calculated using the following expression:

$$
\Delta \mathrm{E}_{\mathrm{ads}}=\left(\mathrm{E}_{\mathrm{P} t 4 \mathrm{CeO} 2}+\mathrm{E}_{\mathrm{O} 2}\right)-\mathrm{E}_{\mathrm{O} 2 / \mathrm{Pt} 4 \mathrm{CeO} 2}
$$

where $\mathrm{E}_{\mathrm{Pt} 4 \mathrm{CeO} 2}, \mathrm{E}_{\mathrm{O} 2}$, and $\mathrm{E}_{\mathrm{O} 2 / \mathrm{Pt} 4 \mathrm{CeO} 2}$ are the total energies of the optimized $\mathrm{Pt}_{4} / \mathrm{CeO}_{2}(111)$, the isolated $\mathrm{O}_{2}$, and the $\mathrm{Pt}_{4} / \mathrm{CeO}_{2}(111)$ with the adsorbed $\mathrm{O}_{2}$, respectively. In determining the reaction pathways, the energy barriers and the transition state (TS) structure of $\mathrm{O}_{2}$, the climbing image nudge elastic band (CI-NEB) $[43,44]$ is used. In this method, the minimum energy path between optimized initial state $\left(\mathrm{O}_{2}\right.$ adsorption), IS and final state (dissociated), FS is obtained. Next, in the search for the TS, the initial and final states were kept fixed while other intermediate states are allowed to relax using force-based optimizers [45] along the "elastic band" until the force exerted on an atom is less than $0.05 \mathrm{eV} / \AA$. The energy barrier is then obtained using the following expression:

$$
\Delta \mathrm{E}_{\mathrm{a}}=\mathrm{E}_{\mathrm{TS}}-\mathrm{E}_{\mathrm{IS}}
$$

where $\mathrm{E}_{\mathrm{IS}}$ and $\mathrm{E}_{\mathrm{TS}}$ are the total energies of the initial state (IS - molecular state) and transition state (TS) of $\mathrm{O}_{2}$ dissociation process on $\mathrm{Pt}_{4} / \mathrm{CeO}_{2}(111)$. Bader charge analysis [46-48] is used to investigate the charge transfer between $\mathrm{Pt}_{4}$ cluster and $\mathrm{CeO}_{2}$ surface, and between the oxygen and $\mathrm{Pt}_{4} / \mathrm{CeO}_{2}(111)$.

\section{Results and Discussions}

\section{1. $\mathrm{Pt}_{4}$ cluster adsorption on $\mathrm{CeO}_{2}(111)$}

We investigated the adsorption of $\mathrm{Pt}_{4}$ on $\mathrm{CeO}_{2}(111)$ by setting up all possible initial adsorption sites of the cluster on the $\mathrm{CeO}_{2}$ surface. In these sites, the $\mathrm{Pt}_{4}$ cluster is either on top of the three-fold $\mathrm{Ce}$, on top of $\mathrm{Ce}$ site or on top of $\mathrm{O}$ site. After optimizing the $\mathrm{Pt}_{4} / \mathrm{CeO}_{2}(111)$ systems using the conjugate gradient method [49], we found that the $\mathrm{Pt}_{4}$ cluster always tends to shift to the most stable position on $\mathrm{CeO}_{2}$ surface, that is, where the center of $\mathrm{Pt}_{4}$ stays on the 
three-fold Ce atoms (or on top of sub-surface oxygen - see Figure 1b) and form three Pt-O-Ce bonds with the $\mathrm{CeO}_{2}(111)$. At this stable position, the $\mathrm{Pt}_{4}$ structure is very symmetric. The $\mathrm{Pt}_{\mathrm{b}}-\mathrm{O}$ bond length (where $\mathrm{Pt}_{\mathrm{b}}$ is the Pt atom that binds with surface) is about $2.01 \AA$. The $\mathrm{Pt}_{\mathrm{b}}-\mathrm{Pt}_{\mathrm{b}}, \mathrm{Pt}_{\mathrm{t}}-\mathrm{Pt}_{\mathrm{b}}$ bond lengths (where $\mathrm{Pt}_{\mathrm{t}}$ is the $\mathrm{Pt}$ atom on top of $\mathrm{Pt}_{4}$ cluster) are $2.63 \AA$ and $2.55 \AA$, respectively. This stable position is in excellent agreement with previous theoretical study of $\mathrm{Pt}_{4}$ on $\mathrm{CeO}_{2}$ [49]. At the most stable site, we calculated the binding energy between $\mathrm{Pt}_{4}$ and $\mathrm{CeO}_{2}$ surface and found to be $-5.28 \mathrm{eV}$. This is much larger than of the binding energy of $\mathrm{Pt}_{4}$ with $\gamma-\mathrm{Al}_{2} \mathrm{O}_{3}(111)$ surface, $-3.55 \mathrm{eV}$, suggesting that $\mathrm{Pt}_{4}$ is more stable on ceria surface than on alumina surface. The Pt-O-Ce bond is composed of the Ce-O bond of bulk ceria and the strong Pt-O bond between $\mathrm{Pt}_{4}$ cluster and the $\mathrm{CeO}_{2}$ surface. The strong Pt-O bond can be attributed to the hybridization of $5 \mathrm{~d}$ states of $\mathrm{Pt}_{\mathrm{b}}$ and $2 \mathrm{p}$ states of $\mathrm{O}$ on top of the $\mathrm{CeO}_{2}$ surface. Here, the $\mathrm{Pt}_{\mathrm{b}}$ and $\mathrm{O}$ atoms share electrons to form a covalent-like bond. The shared electrons between $\mathrm{Pt}_{\mathrm{b}}$ and surface oxygen are shown by the dark region in the charge density difference plot (see Figure 2a). Thus, the Pt-O-Ce bonds act as "anchors" between the surface and the cluster, and stabilize the cluster on the surface. This now confirms the experimental observation that the sintering effect on the Pt particles is significantly suppressed on ceria surface [21,51-52].

For the electronic property of this metal/metal oxide system, we note that an electron charge of $\sim 0.14 \mathrm{e}$ is transferred to $\mathrm{CeO}_{2}$ surface when $\mathrm{Pt}_{4}$ adsorbs. It is also worthwhile to note that, while the adsorbed $\mathrm{Pt}_{4}$ has positive charge, the $\mathrm{Pt}_{\mathrm{t}}$ atom of the cluster exhibits negative charge $(\sim 0.24 \mathrm{e})$. The charge density difference shown in Figure 2 a verifies this. The plot shows the direction of electron charge transfer, from $\mathrm{Pt}_{\mathrm{b}}$ atoms to $\mathrm{CeO}_{2}$ surface and to $\mathrm{Pt}_{\mathrm{t}}$ atom. This charge transfer from Pt cluster to $\mathrm{CeO}_{2}$ surface confirms the trends in charge transfer in previous works $[50,53,54]$. Moreover, we show that due to such charge transfer to $\mathrm{Pt}_{\mathrm{t}}$ and coupling with unpaired electrons of $\mathrm{Pt}_{\mathrm{t}}$, the $\mathrm{Pt}_{\mathrm{t}}$ atom holds smaller spin moments as compared to the corresponding $\mathrm{Pt}$ atom of the isolated $\mathrm{Pt}_{4}$ cluster. The total spin moments of $\mathrm{Pt}_{4} \mathrm{CeO}_{2}$ system $\left(2.24 \mu_{\mathrm{B}}\right)$ is lower as compared to the isolated $\mathrm{Pt}_{4}\left(2.83 \mu_{\mathrm{B}}\right)$. In addition, from Figure $2 \mathrm{~b}$, the spin density mainly comes from the $\mathrm{Pt}_{4}$ and the spin density $\mathrm{Pt}_{\mathrm{t}}$ is lower as compared to that of $\mathrm{Pt}_{\mathrm{b}}$ atom.

\section{2. $\mathrm{O}_{2}$ adsorption on $\mathrm{Pt}_{4} / \mathrm{CeO}_{2}(111)$}

\subsubsection{Molecular adsorption}


Next, for the adsorption of $\mathrm{O}_{2}$ on $\mathrm{Pt}_{4} / \mathrm{CeO}_{2}(111)$, we considered all possible initial adsorption sites. The $\mathrm{Pt}_{4} \mathrm{CeO}_{2}$ system is based on the optimized structure discussed in the previous section. Initial configurations of $\mathrm{O}_{2}$ molecule takes into account conformation via: (1) direct interaction with the $\mathrm{CeO}_{2}$ surface; (2) interaction with the $\mathrm{Pt}_{4}$ only and (3) interaction with both. After optimizing and examining binding energies of different adsorption sites of $\mathrm{O}_{2}$ on $\mathrm{Pt}_{4} \mathrm{CeO}_{2}$, four sites that have much larger adsorption energies compared to the rest are shown in Figure 3. The adsorption energies for these sites are listed in Table 1. We can see that the highest adsorption energy of $\mathrm{O}_{2}$ on $\mathrm{Pt}_{4} / \mathrm{CeO}_{2}$ is found at site $4(-1.39 \mathrm{eV})$, where $\mathrm{O}_{2}$ binds with $\mathrm{Pt}_{\mathrm{b}}$ at the vertex of the cluster. Next stable configuration is in site $2(-0.97 \mathrm{eV})$, where the $\mathrm{O}_{2}$ binds to the $\mathrm{Pt}_{\mathrm{t}}-\mathrm{Pt}_{\mathrm{b}}$ edge of the cluster. The adsorption energies of sites 1,2 , and 3 range from $-0.85 \mathrm{eV}$ to $0.97 \mathrm{eV}$ (i.e. quite close with each other), which are comparable to the other studies of $\mathrm{O}_{2}$ adsorption on isolated $\mathrm{Pt}_{3}$ cluster $(-1.08 \mathrm{eV})$ [55] and isolated $\mathrm{Pt}_{\mathrm{n}}(\mathrm{n}=2-5)$ cluster $(-0.53$ to 0.83 eV) [56]. The significant large adsorption energy of site 4 as compared to other sites is attributed to the repulsion of $\mathrm{O}_{2}$ with the oxygen of $\mathrm{CeO}_{2}$ surface, which directly bonds with $\mathrm{Pt}_{\mathrm{b}}$ at the vertex of the cluster. This pushes $\mathrm{O}_{2}$ molecule far away from surface and strongly reconstructs the $\mathrm{Pt}_{\mathrm{b}}-\mathrm{O}$ bond of cluster with surface (Figure 3). We also checked the contribution coming from the reconstruction of the cluster and the surface (i.e. if reconstruction causes the large difference in the adsorption energies between site 4 and the rest of the sites), we perform calculations where the surface and the cluster were kept fixed while $\mathrm{O}_{2}$ molecule is relaxed in all directions. We note that the difference in adsorption energies of sites 1, 2, 3 and 4 is within $0.10 \mathrm{eV}$. Thus, the adsorption energy of $\mathrm{O}_{2}$ on $\mathrm{Pt}_{4} / \mathrm{CeO}_{2}$ can be affected by the reconstruction of $\mathrm{Pt}_{4}$ cluster.

Next, upon oxygen adsorption on $\mathrm{Pt}_{4} \mathrm{CeO}_{2}$, the bond length of $\mathrm{O}_{2}$ molecule ( $\mathrm{d}_{\mathrm{O}-\mathrm{O}}$ in Table 1) is significantly elongated. The largest elongation is obtained from site 3 , which is about 1.46 $\AA$ ( $19 \%$ longer as compared to the O-O bond length in gas state). The elongation of O-O bond can be explained by the electron charge transfer from $\mathrm{Pt}_{4}$ to $\mathrm{O}_{2}$ molecule and the possibility of intra-molecular spin transition between $\mathrm{O}_{2}$ molecule itself [57]. Since, the anti-bonding orbitals $\left(\pi^{*}\right)$ in $\mathrm{O}_{2}$ are singly occupied, therefore, the charge transfer to these orbitals makes the O-O bond longer. We can see the relation between the negative charge (estimated by Bader analysis) on $\mathrm{O}_{2}$ and the $\mathrm{O}-\mathrm{O}$ bond length in Table 1. The bigger is the negative charge on $\mathrm{O}_{2}$, the longer is the $\mathrm{O}-\mathrm{O}$ bond. To further examine the adsorption state of $\mathrm{O}_{2}$ on $\mathrm{Pt}_{4} \mathrm{CeO}_{2}$, we calculated the stretching frequencies of $\mathrm{O}-\mathrm{O}$ bond ( $\mathrm{f}_{\mathrm{O}-\mathrm{O}}$ in Table 1 ) and the spin density in Figure 4. For site 3 , 
where $\mathrm{O}_{2}$ binds to the $\mathrm{Pt}_{\mathrm{b}}-\mathrm{Pt}_{\mathrm{b}}$ edge of the cluster, the $\mathrm{O}-\mathrm{O}$ stretching frequency is found to be 694 $\mathrm{cm}^{-1}$, which is a typical value for a peroxide state of $\mathrm{O}_{2}\left(690-700 \mathrm{~cm}^{-1}\right)$ [58,59], involving full occupation of singly occupied $\pi^{*}$ orbitals. As a result, $\mathrm{O}_{2}$ in this state is nonmagnetic. This can be confirmed from Figure 4 where there is no spin density found in adsorbed $\mathrm{O}_{2}$ for this site. For sites 1, 2 and 4, the stretching frequencies are about $1047 \mathrm{~cm}^{-1}, 757 \mathrm{~cm}^{-1}$, and $1035 \mathrm{~cm}^{-1}$, respectively. Thus, at site $2, \mathrm{O}_{2}$ is in between superoxide $\left(860-880 \mathrm{~cm}^{-1}\right)$ [60] and peroxide states; at sites 1 and 4, $\mathrm{O}_{2}$ is in between neutral $\left(1556 \mathrm{~cm}^{-1}\right)$ [61] and superoxide states. For these states, $\mathrm{O}_{2} \pi^{*}$ orbitals are not fully filled and, hence, the $\mathrm{O}_{2}$ molecule still holds a magnetic moment. Figure 4 shows a noticeable spin density in $\mathrm{O}_{2}$ at sites 1,2 and 4.

\subsubsection{Dissociation of $\mathrm{O}_{2}$}

In this section, we focus on the dissociation of $\mathrm{O}_{2}$ molecule from the molecularly adsorbed state, or the so-called molecular precursor state (MPS). Four paths are considered based on the four initial states obtained from the four molecular adsorption states of $\mathrm{O}_{2}$ discussed in the previous section (see Figure 3). Here, we labeled the paths as path1, path 2, path 3 and path 4 (two of which start at Pt-Pt edge sites $\left\{\mathrm{Pt}_{\mathrm{b}}-\mathrm{Pt}_{\mathrm{b}}, \mathrm{Pt}_{\mathrm{t}}-\mathrm{Pt}_{\mathrm{b}}\right\}$ and the other two at the Pt vertex sites $\left\{\mathrm{Pt}_{\mathrm{t}}, \mathrm{Pt}_{\mathrm{b}}\right\}$ of the cluster) (see Figure 5). The final states of the dissociation process are also optimized and are shown in Figure 5. Then the energy barrier for each path of the $\mathrm{O}_{2}$ dissociation process is obtained using CI-NEB and is shown in Table 2 and Figure 6. We note that $\mathrm{O}_{2}$ prefers to dissociate via Pt-Pt edge sites (Path 2 and 3). The energy barriers are found to be $0.42 \mathrm{eV}$ (path 2) and $0.17 \mathrm{eV}$ (path 3). These values are much smaller than those of path $1(1.50 \mathrm{eV})$ and path $4(1.93 \mathrm{eV})$. Thus $\mathrm{O}_{2}$ dissociates easiest at path 3. Looking at the charge transfer $(\Delta \mathrm{Q})$ from $\mathrm{Pt}_{4} \mathrm{CeO}_{2}$ to $\mathrm{O}_{2}$ molecule and the O-O bond elongation ( $\mathrm{d}_{\mathrm{O}-\mathrm{O}}$ ) at the MPS in Table 1, we note that there is good correlation between charge transfer and bond elongation of $\mathrm{O}_{2}$ molecule at the MPS states with the dissociation barriers. The higher is the charge transfer to $\mathrm{O}_{2}$ in MPS (longer O-O bond length), the lower the energy barriers we obtain. Due to the highest charge transfer from $\mathrm{Pt}_{4} \mathrm{CeO}_{2}$ to $\mathrm{O}_{2}$ in site 3 , the barrier is lowest in the corresponding dissociation path 3. In general, the dissociation of $\mathrm{O}_{2}$ is easier at the edge sites than at the vertex sites of Pt cluster and that the O-O bond stretching and breaking strongly depends on the initial molecular adsorption site of $\mathrm{O}_{2}$. 
To further understand the effect of the $\mathrm{CeO}_{2}$ support to the catalytic reactivity of the $\mathrm{Pt}_{4}$ cluster, we performed energy barrier calculation for $\mathrm{O}_{2}$ dissociation on the edge site of the $\mathrm{Pt}_{4}$ cluster without the presence of $\mathrm{CeO}_{2}$ support (see Figure 7). Due to the symmetry of isolated $\mathrm{Pt}_{4}$ cluster, there is only one reaction path at the edge site. This site is related to paths 2 and 3 in $\mathrm{Pt}_{4} / \mathrm{CeO}_{2}$ (111). It is found that the activation barrier for $\mathrm{O}_{2}$ dissociation at edge site of isolated $\mathrm{Pt}_{4}$ is about $0.12 \mathrm{eV}$. This is lower than when $\mathrm{CeO}_{2}$ support is present (i.e. $0.17 \mathrm{eV}$ for path 3 ). This indicates that, dissociation occurs more easily in the isolated $\mathrm{Pt}_{4}$ than in the $\mathrm{Pt}_{4} / \mathrm{CeO}_{2}(111)$. We attribute the suppressed reactivity of $\mathrm{Pt}_{4} / \mathrm{CeO}_{2}(111)$ to the support itself. To verify the electronic effect of the support, the local density of states (LDOS) plot for the isolated Pt cluster and for the $\mathrm{Pt}_{4} / \mathrm{CeO}_{2}(111)$ is shown in Figure 8. In order to compare the local density of states (LDOS) of the isolated $\mathrm{Pt}_{4}$ cluster with the supported cluster for further use, we broadened the energy eigenvalue spectrum of the isolated cluster obtained from the Kohn-Sham energy states by using Gaussian function. The LDOS of the two clusters are directly comparable as we used the same broadening parameter for both (with the width of the smearing is set to $0.2 \mathrm{eV}$ ). Without the support (isolated $\mathrm{Pt}_{4}$ ), a sharp spin down 5d- states at the Fermi level can be noted. This state is reactive and can hybridize with $2 \mathrm{p}$ states of oxygen. On the other hand, when $\mathrm{Pt}_{4}$ is on the support, the $5 \mathrm{~d}$ states at the Fermi level of $\mathrm{Pt}$ atoms $\left(\mathrm{Pt}_{\mathrm{t}}\right.$ and $\left.\mathrm{Pt}_{\mathrm{b}}\right)$ in $\mathrm{Pt}_{4} / \mathrm{CeO}_{2}(111)$ have lower density and are more broadened, indicating lesser reactivity. This mechanism for the suppression of the reactivity of the $\mathrm{Pt}_{4}$ cluster towards $\mathrm{O}_{2}$ dissociation might be extended for other metal oxide supports as long as the bonding conditions such as the formation of Pt-O bonds of the cluster and the support is ensured. Our previous work shows that, when $\mathrm{Pt}_{4}$ binds to $\mathrm{Al}_{2} \mathrm{O}_{3}$ surface via Pt-Al bonds, the oxide support does not significantly alter the catalytic reactivity properties of the the $\mathrm{Pt}_{4}$ cluster toward NO molecule [62].

\section{Conclusion}

The reactivity of $\mathrm{Pt}_{4} / \mathrm{CeO}_{2}(111)$ towards oxygen as well as the geometry and the electronic property of the $\mathrm{Pt}_{4} / \mathrm{CeO}_{2}(111)$ system is investigated using density functional theory with inclusion of the Hubbard parameter, $\mathrm{U}(\mathrm{DFT}+\mathrm{U})$. We found that, $\mathrm{Pt}_{4}$ cluster strongly binds and thus can act as "anchor" to prevent sintering effect in catalyst confirming experiments. The adsorption of $\mathrm{Pt}_{4}$ on $\mathrm{CeO}_{2}(111)$ involves a direction of electron charge transfer from $\mathrm{Pt}_{\mathrm{b}}$ atoms to 
$\mathrm{CeO}_{2}$ surface as well as $\mathrm{Pt}_{\mathrm{t}}$ atom. This charge transfer to $\mathrm{Pt}_{\mathrm{t}}$ allows coupling with its unpaired electrons thereby it holds smaller spin moments as compared to the corresponding Pt atom of the isolated $\mathrm{Pt}_{4}$ cluster. Moreover, when $\mathrm{O}_{2}$ adsorbs on $\mathrm{Pt}_{4} / \mathrm{CeO}_{2}(111)$, we found that it prefers vertex site at the bottom of $\mathrm{Pt}_{4}$ cluster, $\mathrm{Pt}_{\mathrm{b}}$. However, $\mathrm{O}_{2}$ gains a large amount of electron charge when it adsorbs at the Pt-Pt edges. As a result, the O-O bond at the edges is more elongated. At $\mathrm{Pt}_{\mathrm{b}}-\mathrm{Pt}_{\mathrm{b}}$ edge site, where the $\mathrm{O}_{2}$ molecule is elongated the most, is in peroxide state with no spin density, while, the magnetic properties are still evident in the other sites. Furthermore, $\mathrm{O}_{2}$ molecule prefers to dissociate at the Pt-Pt edges of the cluster than at the vertexes. And these barriers are higher than in an isolated $\mathrm{Pt}_{4}$. The lower activation barrier in the $\mathrm{CeO}_{2}$-supported $\mathrm{Pt}_{4}$ cluster is due to the sharp spin down $5 \mathrm{~d}$ - states at the Fermi level of the isolated cluster. When the $\mathrm{Pt}_{4}$ adsorbs on the $\mathrm{CeO}_{2}$ surface, the hybridization of $5 \mathrm{~d}$ orbitals of $\mathrm{Pt}_{4}$ with $2 \mathrm{p}$ orbitals of oxygen in $\mathrm{CeO}_{2}(111)$ leads to the decrease of those active $5 \mathrm{~d}$ states. Hence, there is a suppression of the reactivity of the $\mathrm{Pt}_{4}$ cluster due to the $\mathrm{CeO}_{2}$ support.

\section{Acknowledgements}

This work is supported by MEXT (Ministry of Education, Culture, Sports, Science and Technology of Japan) through QED (Quantum Engineering Design) program. M.C.S. Escaño extends gratitude to Tenure Track Program for Innovative Research, Ministry of Education, Culture, Sports, Science and Technology, Japan (MEXT) and Japan Science and Technology Agency (JST). Some of the calculations presented here were done using the computer facilities at the following institutes: Cybermedia Center (Osaka University); ISSP Supercomputer Center (University of Tokyo); High Energy Accelerator Research Organization (KEK) under support of its Large Scale Simulation Program (No. 12/13-10). 


\section{References}

[1] K. C. Taylor: Catal. Rev. - Sci. Eng. 35 (1993) 457.

[2] M. Shelef, G. W. Graham: Catal. Rev. - Sci. Eng. 36 (1994) 433.

[3] D. R. Rainer, M. Koranne, S. M. Vesecky, D. W. Goodman: J. Phys. Chem. B 101 (1997) 10769.

[4] S. S. C. Chuang, C. D. Tan: Catal. Today 35 (1997) 369.

[5] H. C. Yao, Y. F. Yu. Yao: J. Catal. 86 (1984) 254.

[6] A. Trovarelli: Catal. Rev. - Sci. Eng. 38 (1996) 439.

[7] J. Kaspar, P. Fornasiero, M. Graziani: Catal. Today 50 (1999) 285.

[8] E.C. Su, W.G. Rothschild: J. Catal. 99 (1984) 506.

[9] L. L. Murrell, S. J. Tauster, D. R. Anderson: Stud. Surf. Sci. Catal. 71 (2001) 275.

[10] A. F. Diwell, R. R. Rajaram, H. A. Shaw, T. J. Truex: Stud. Surf. Sci. Catal. 71 (2001) 139.

[11] H. Shinjoh, M. Hatanaka, Y. Nagai, T. Tanabe, N. Takahashi, T. Yoshida, Y. Miyake: Top. Catal. 52 (2009) 1967.

[12] M. Ozawa, M. Kimura, A. Isogai: J. Alloys Compd. 193 (1993) 73.

[13] T. Q. Nguyen, M. C. S. Escano, N. Shimoji, H. Nakanishi, H. Kasai: Phys. Rev. B 77 (2008) 195307.

[14] M. C. S. Escano, H. Nakanishi, H. Kasai: J. Phys. Chem. A 113 (2009) 14302.

[15] M. C. S. Escano, T. Q. Nguyen, H. Nakanishi, H. Kasai: Surf. Sci. 602 (2008) 3415.

[16] B. Yoon, H. Hakkinen, U. Landman: J. Phys. Chem. A 107 (2003) 4066.

[17] T. Halachev, E. Ruckenstein: J. Mol. Catal. 16 (1982) 149. 
[18] Y. Jiang, J. B. Adams, M. V. Schilfgaarde: J. Chem. Phys. 123 (2005) 0640701

[19] T. X. T. Sayle, S. C. Parker, C. R. A. Catlow: Surf. Sci. 316 (1994) 329

[20] H. Nörenberg, J. H. Harding: Surf. Sci. 477 (2011) 17

[21] Y. Nagai, T. Hirabayashi, K. Dohmae, N. Takagi, T. Minami, H. Shinjoh, S. Matsumoto: J. Catal. 242 (2006) 103.

[22] T. Li, P. B. Balbuena: J. Phys. Chem. B 105 (2001) 9943

[23] D. Dai, K. Balasubramanian: J. Chem. Phys. 103 (1995) 648

[24] O. Pozdnyakova, D. Teschner, A. Wootsch, J. Krohnert, B. Steinhauer, H. Sauer, L. Toth, F. C. Jentoft, A. Knop-Gericke, Z. Paal, R. Schlogl: J. Catal. 237 (2006) 1

[25] G. Kresse, J. Hafner: Phys. Rev. B 47 (1993) 558.

[26] G. Kresse, J. Furthmuller: Phys. Rev. B 54 (1996) 111169.

[27] J. P. Perdew, K. Burke, M. Ernzerhof: Phys. Rev Lett. 77 (1996) 3865.

[28] G. Kresse, J. Joubert: Phys. Rev. B 59 (1999) 1758.

[29] P. E. Blochl: Phys. Rev. B 50 (1994) 17953.

[30] H. H. Monkhorst, J. D. Pack: Phys. Rev. B 13 (1976) 5188.

[31] S. L. Dudarev, G. A. Botton, S. Y. Savrasov, C. J. Humphreys, A. P. Sutton: Phys. Rev. B 57 (1998) 1505.

[32] Y. L. Lee, J. Kleis, J. Rossmeisl, D. Morgan: Phys. Rev. B 80 (2009) 224101

[33] M. Nolan, S. Grigoleit, D. C. Sayle, S. C. Parker: Surf. Sci. 576 (2005) 217.

[34] S. Lany, A. Zunger: Phys. Rev. B 80 (2009) 085202.

[35] B. J. Morgan, G. W. Watson: Phys. Rev. B 80 (2009) 233102.

[36] M. Nolan, G. W. Watson: J. Chem. Phys. 125 (2006) 144701.

[37] D. O. Sanlon, A. Walsh, B. J. Mogan, M. Nolan, J. Fearon, G. W. Watson: J. Phys. Chem. C 
$111(2007) 7971$.

[38] B. J. Morgan, G. W. Watson: J. Phys. Chem. C 114 (2010) 2321.

[39] J. J. Plata, A. M. Marquez, J. F. Sanz: J. Chem. Phys 136 (2012) 041101.

[40] E. A. Kummerle, G. Heger: J. Solid State Chem. 147 (1999) 485.

[41] J. Schmidt, Ch. Stuhlmann, H. Ibach: Surf. Sci. 284 (1993) 121.

[42] C. Jung, H. Tsuboi, M. Koyama, M. Kubo, E. Broclawik, A. Miyamoto: Catal. Today 111 (2006) 322.

[43] G. Henkelman, B. P. Uberuaga, H. Jonsson: J. Chem. Phys. 113 (2000) 9901.

[44] G. Henkelman, H. Jonsson: J. Chem. Phys. 113 (2000) 9978.

[45] P. Pulay: Chem. Phys. Lett. 73 (1980) 393.

[46] R. Bader: Atoms in Molecules: A Quantum Theory (Oxford University Press, New York, 1990)

[47] G. Henkelman, A. Arnaldsson, H. Jonsson: Comput. Mater. Sci. 36 (2006) 354.

[48] E. Sanville, S. D. Kenny, R. Smith, G. Henkelman: J. Comput. Chem. 28 (2007) 899.

[49] M. R. Hestenes, E. Stiefel: J. Res. Natl. Bur. Stand. 49 (1952) 2379.

[50] Z. Lu, Z. Yang: J. Phys.: Condens. Matter 22 (2010) 475003.

[51] C. H. Bartholomew: Appl. Catal. A 212 (2001) 17.

[52] H. Birgersson, L. Eriksson, M. Boutonnet, S. G. Jaras: Appl. Catal. B 54 (2004) 193.

[53] C. Jung, R. Ishimoto, H. Tsuboi, M. Koyama, A. Endou, M. Kubo, C. A. D. Carpio, A. Miyamoto: Appl. Catal. A: General 305 (2006) 102.

[54] M. Alfredsson, C. R. A. Catlow: Phys. Chem. Chem. Phys. 4 (2002) 6100.

[55] P. B. Balbuena, D. Altomare, L. Agapito, J. M. Seminario: J. Phys. Chem. B 107 (2003) 13671. 
[56] T. Li, P. B. Balbuena: J. Phys. Chem. B 105 (2001) 9943.

[57] L. Qi, X. Quian, J. Li: Phys. Rev. Lett 101 (2008) 146101.

[58] H. Steininger, S. Lehwald, H. Ibach: Surf. Sci. 123 (1982) 1.

[59] D. A. Outka, J. Stohr, W. Jark, P. Stevens, J. Solomon, R. J. Madix: Phys. Rev. B 35 (1987) 4119.

[60] J. L. Gland, B. A. Sexton, G. B. Fisher: Surf. Sci. 95 (1980) 587.

[61] A. Weber, E. A. McGinnis: J. Mol. Spectro. 4 (1960) 195.

[62] F. Oemry, M. C. Escano, H. Kishi, S. Kunikata, H. Nakanishi, H. Kasai, H. Maekawa, K. Osumi, Y. Tashiro: J. Nanosci. Nanotechnol. 11 (2011) 2844 


\section{Figure Caption(s):}

Figure 1. (a) Side view and (b) top view of the most stable structure of $\mathrm{Pt}_{4}$ on $\mathrm{CeO}_{2}(111) \mathrm{p} 3 \times 3$ surface. $\mathrm{Pt}_{\mathrm{t}}$ and $\mathrm{Pt}_{\mathrm{b}}$ represent the $\mathrm{Pt}$ atoms, which are on top and at the bottom (binds with surface oxygen) of the cluster, respectively. The $\mathrm{Pt}, \mathrm{Ce}$ and $\mathrm{O}$ atoms are labeled accordingly.

Figure 2. (a) Charge density redistribution and (b) spin density in $\mathrm{Pt}_{4} / \mathrm{CeO}_{2}(111)$ system. For charge density redistribution (a), the dark and bright regions represent the increase and decrease of electron charge, respectively. For the spin density (b), the dark and bright regions depict spinup and spin-down electrons, respectively. The iso-surface value is $0.005 \mathrm{e} / \AA^{3}$.

Figure 3. The four most stable adsorption configuration of $\mathrm{O}_{2}$ on $\mathrm{Pt}_{4}$ supported by $\mathrm{CeO}_{2}$ surface. The legend for adsorbed $\mathrm{O}_{2}, \mathrm{Pt}$, $\mathrm{Ce}$ and $\mathrm{O}\left(\right.$ of $\left.\mathrm{CeO}_{2}\right)$ are labeled accordingly.

Figure 4. Spin density on different adsorption sites of $\mathrm{O}_{2}$ on $\mathrm{Pt}_{4} / \mathrm{CeO}_{2}(111)$. The dark and bright regions show the spin-up and spin-down electron density; respectively The iso-surface value is $0.005 \mathrm{e} / \AA ̊$.

Figure 5. The optimized final (FS) and initial (IS) states of $\mathrm{O} 2$ dissociation on $\mathrm{Pt}_{4} / \mathrm{CeO}_{2}(111)$.

Figure 6: Reaction energy diagram for $\mathrm{O}_{2}$ dissociation on $\mathrm{Pt}_{4} / \mathrm{CeO}_{2}(111)$ at four different pathways (Path 1, Path 2, Path 3, Path 4). The adsorbed oxygen is labeled with (x).

Figure 7: Reaction energy diagram for $\mathrm{O}_{2}$ dissociation on isolated $\mathrm{Pt}_{4}$ cluster at $\mathrm{Pt}-\mathrm{Pt}$ edge site. Oxygen is the smaller sized atom.

Figure 8. Local density of states (LDOS) of $\mathrm{Pt}$ atoms in isolated $\mathrm{Pt}_{4}$ cluster and $\mathrm{Pt}_{4} / \mathrm{CeO}_{2}$. The upper and the bottom panels correspond to spin-up and spin-down electrons, respectively. The Fermi level is shifted to zero. 
Table I. The adsorption energies $\left(\Delta \mathrm{E}_{\mathrm{ads}}\right)$, the $\mathrm{O}-\mathrm{O}$ bond lengths $\left(\mathrm{d}_{\mathrm{O}-\mathrm{O}}\right)$, the $\mathrm{O}-\mathrm{O}$ stretching frequencies ( $\mathrm{f}_{\mathrm{O}-\mathrm{O}}$ ), and the charge transfer to the adsorbed $\mathrm{O}_{2}$ molecule on $\mathrm{CeO}_{2}$ supported $\mathrm{Pt}_{4}$ cluster at Site 1, Site 2, Site 3, Site 4 (corresponding to Figure 3).

\begin{tabular}{ccccc}
\hline Site & $\Delta \mathrm{E}_{\mathrm{ads}}(\mathrm{eV})$ & $\mathrm{d}_{\mathrm{O}-\mathrm{O}}(\AA)$ & $\mathrm{f}_{\mathrm{O}-\mathrm{O}}\left(\mathrm{cm}^{-1}\right)$ & $\Delta \mathrm{Q}(\mathrm{e})$ \\
\hline 1 & -0.91 & 1.36 & 1047 & -0.53 \\
2 & -0.97 & 1.41 & 757 & -0.69 \\
3 & -0.85 & 1.46 & 694 & -0.88 \\
4 & -1.39 & 1.37 & 1035 & -0.57 \\
\hline
\end{tabular}


Table II. Activation barriers $\left(\Delta \mathrm{E}_{\mathrm{a}}\right)$, the $\mathrm{O}-\mathrm{O}$ bond distances $\left(\mathrm{d}_{\mathrm{O}-\mathrm{O}}\right)$ for initial (IS), transition (TS) and final states (FS) for the dissociation of $\mathrm{O}_{2}$ molecule on $\mathrm{CeO}_{2}$ supported $\mathrm{Pt}_{4}$ cluster at Path 1 , Path 2, Path 3, Path 4 (corresponding to Figure 5)

\begin{tabular}{ccccc}
\hline \multirow{2}{*}{ Path } & $\Delta \mathrm{E}_{\mathrm{a}}(\mathrm{eV})$ & \multicolumn{3}{c}{$\mathrm{d}_{\mathrm{O}-\mathrm{O}}(\AA)$} \\
\cline { 3 - 5 } & & $\mathrm{IS}$ & $\mathrm{TS}$ & $\mathrm{FS}$ \\
\hline 1 & 1.51 & 1.36 & 2.01 & 3.85 \\
2 & 0.42 & 1.41 & 2.01 & 5.30 \\
3 & 0.17 & 1.46 & 2.35 & 5.22 \\
4 & 1.93 & 1.37 & 2.24 & 3.85 \\
\hline
\end{tabular}


Figure 1:

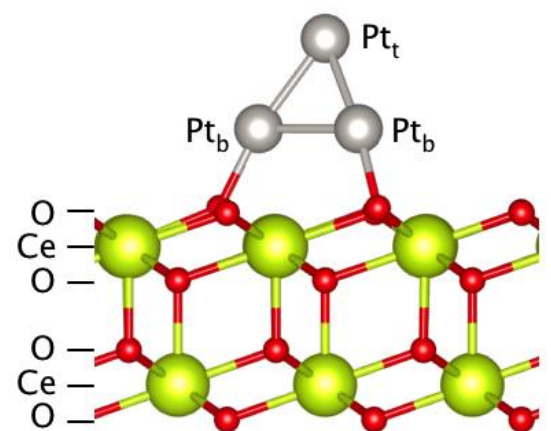

(a)

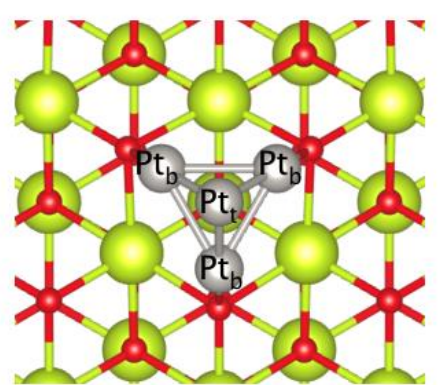

(b)

Figure 2:

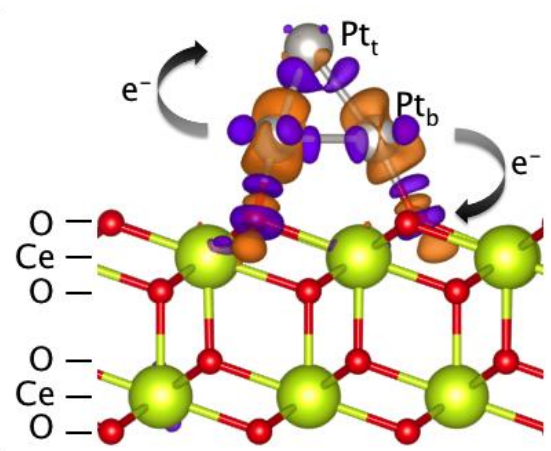

(a)

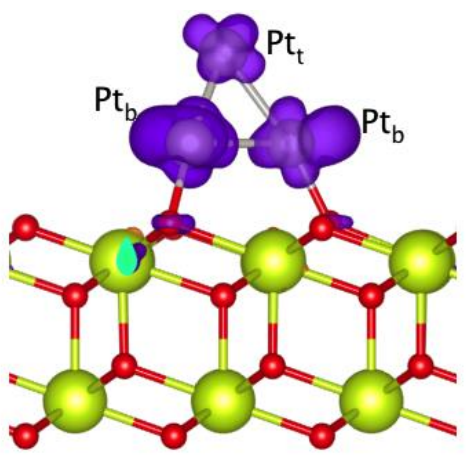

(b)

Figure 3:

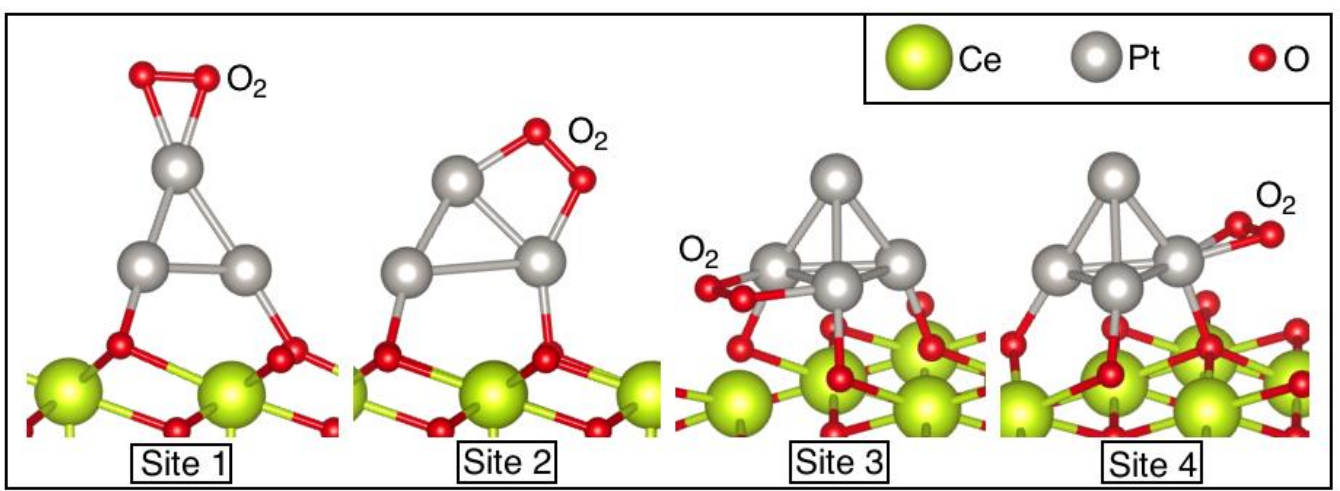


Figure 4:

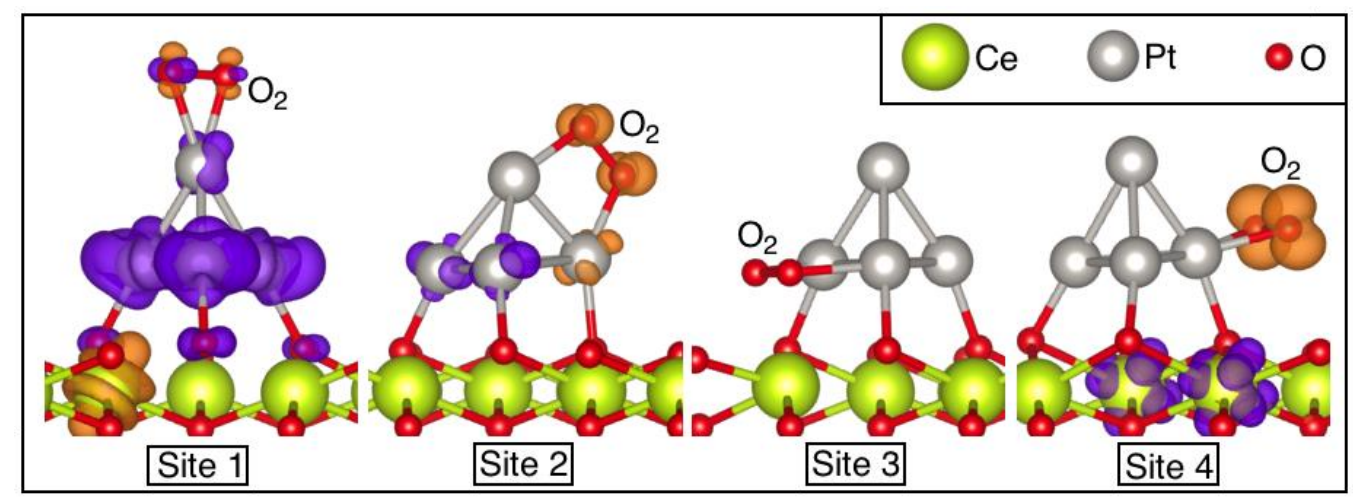

Figure 5:

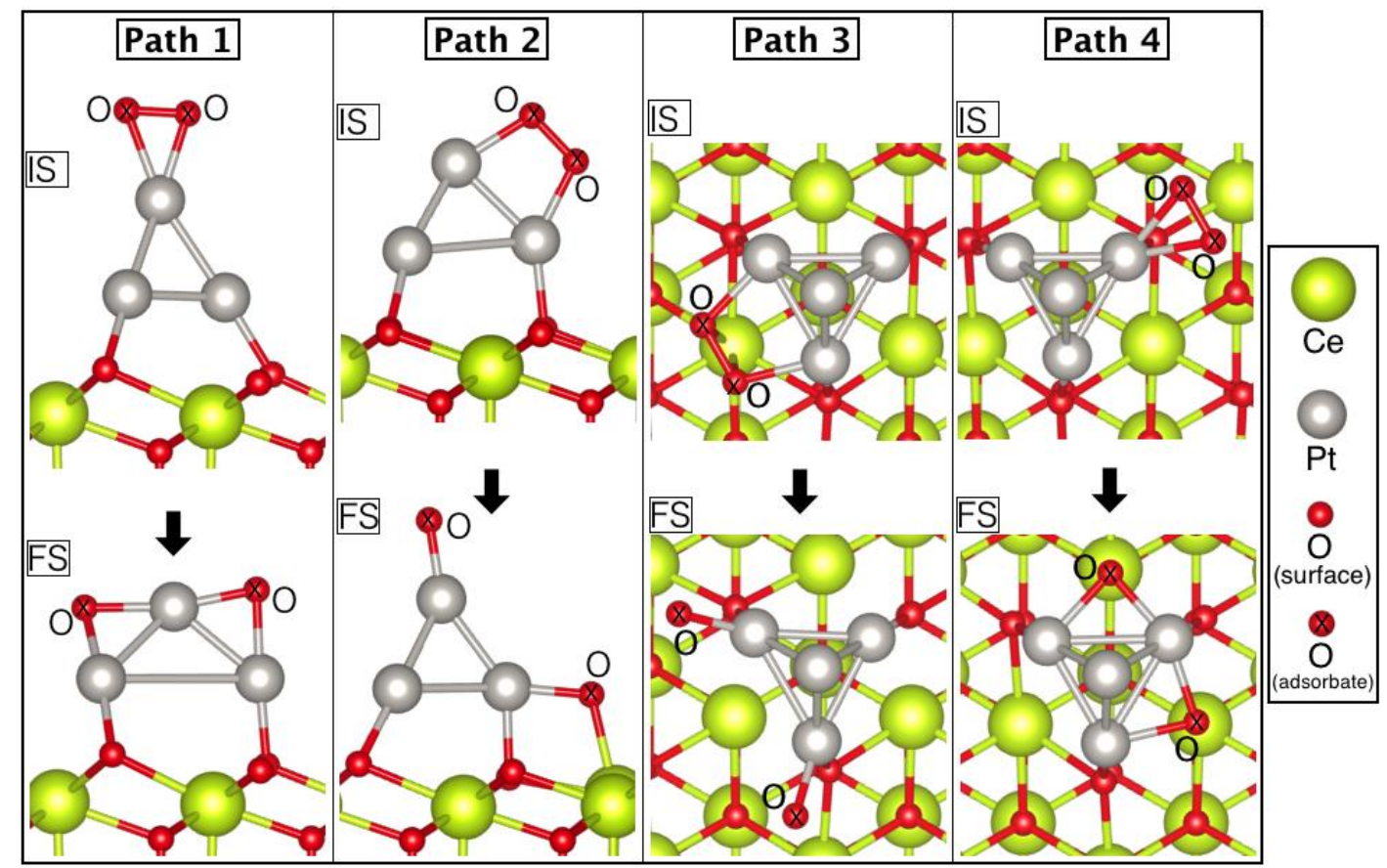


Figure 6:

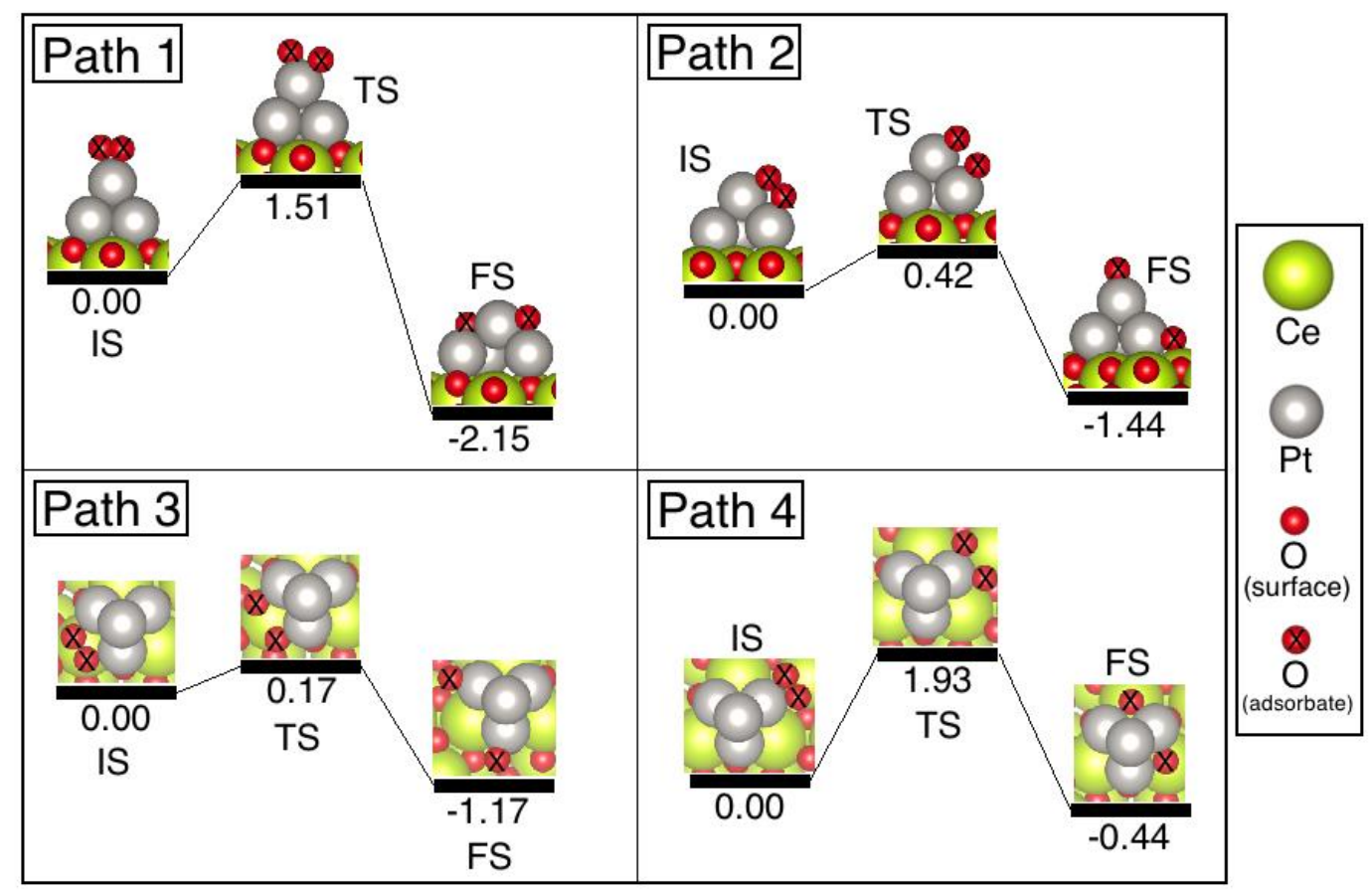

Figure 7:

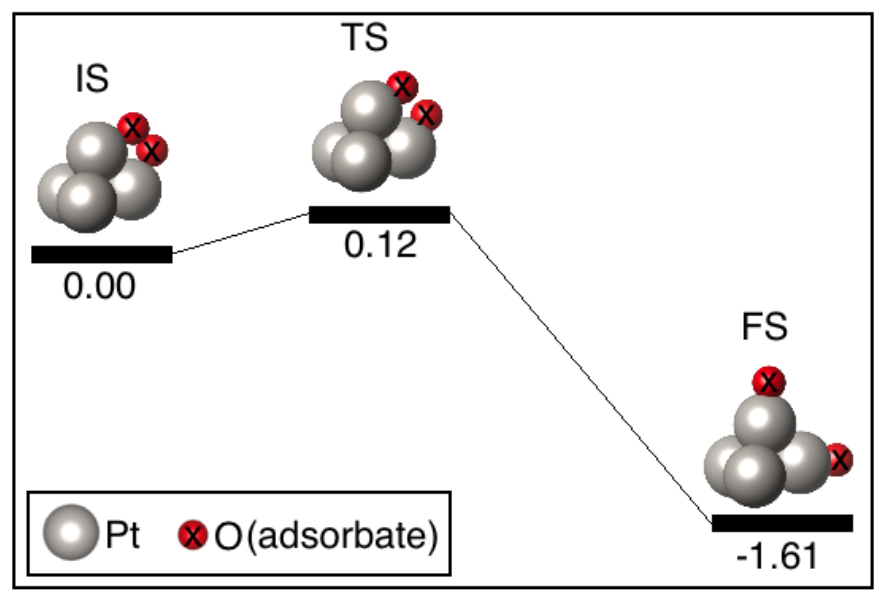


Figure 8:

LDOS of Pt atoms in isolated \& supported cluster

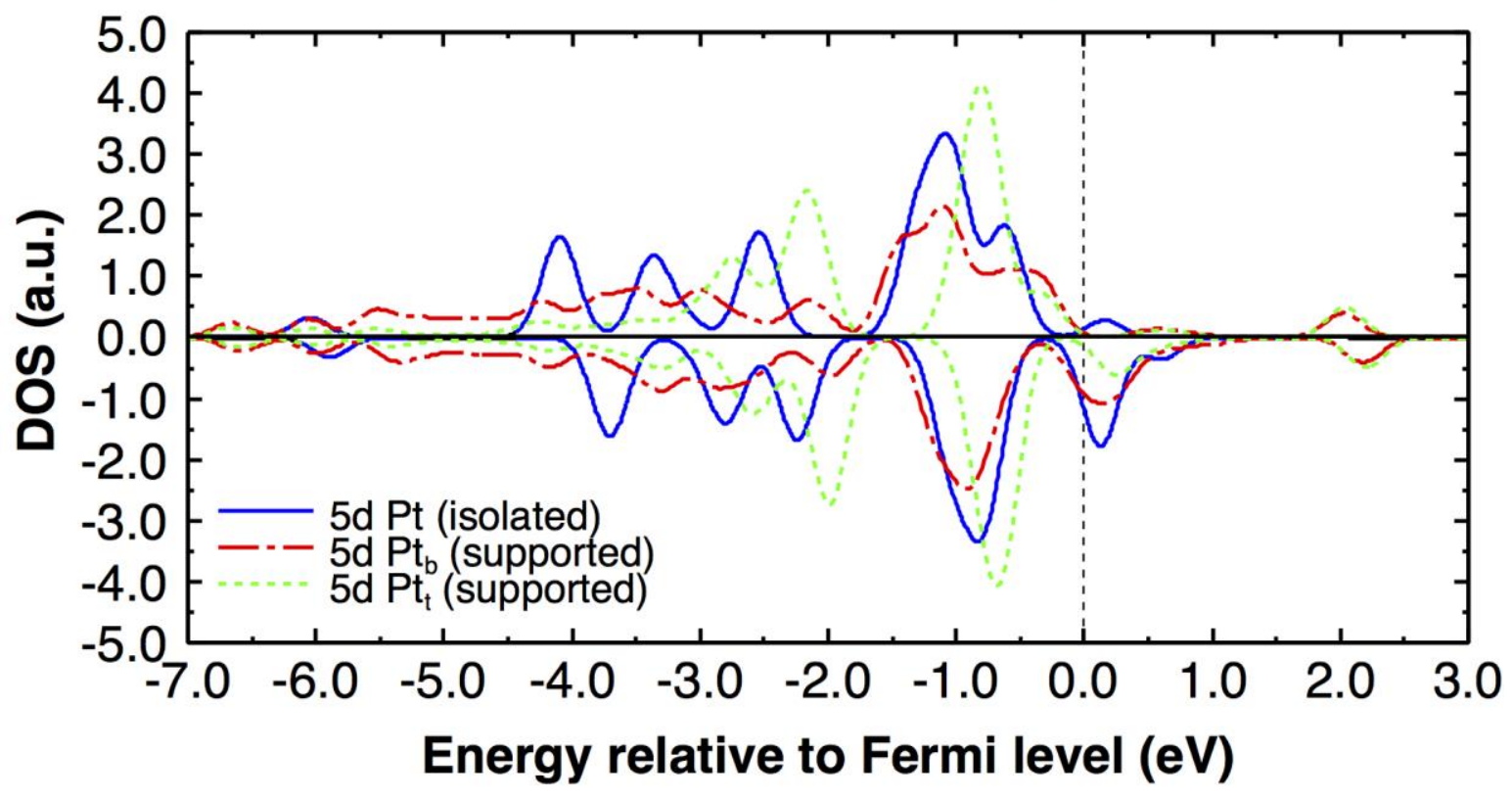

